\title{
Risk Reducing-Mastectomy: Experience of a University Hospital in Argentina
}

\section{McLean IL ${ }^{1 *}$, Montoya $\mathrm{D}^{1}$, Beccar Varela $\mathrm{E}^{1}$, Morris $\mathrm{B}^{1}$, Barber $\mathrm{J}^{1}$, Condins $\mathrm{C}^{1}$, Constanza Vallone $\mathrm{M}^{2}$, Berdinelli $\mathrm{D}^{3}$, García Suarez $\mathrm{P}^{4}$, Schejtman $\mathrm{D}^{4}$ and McLean $\mathrm{LH}^{1}$}

${ }^{1}$ Breast Surgery Service, Centro Mamario del Hospital Universitario Austral, Argentina

${ }^{2}$ Genetic Service, Centro Mamario del Hospital Universitario Austral, Argentina

${ }^{3}$ Mental Health, Centro Mamario del Hospital Universitario Austral, Argentina

${ }^{4}$ Breast Imaging Service, Centro Mamario del Hospital Universitario Austral, Argentina

\section{Research Article}

Volume 4 Issue 2

Received Date: June 29, 2020

Published Date: August 10, 2020

DOI: $10.23880 /$ ijtps-16000149

*Corresponding author: Ignacio L McLean, Director of Breast Center, Hospital Universitario Austral, Avenida Pte Perón 1500 (1629) Pilar, Buenos Aires Province, Argentina, Email: imclean@cas.austral.edu.ar

\section{Abstract}

Background: The number of risk-reducing mastectomies (RRM) has increased over the past years as genetic testing has become more readily available.

Objective: The aim of this study was to analyze the experience of a University Hospital in Argentina

Material and methods: The analysis included healthy patients undergoing simultaneous bilateral RRM and those with a history of breast cancer who underwent contralateral RRM. Patients with mastec $\neg$ tomies performed as treatment of breast cancer were not considered, but those with contralateral mastectomies were included.

Results: Seventy RRM were performed in 49 patients who fulfilled the inclusion criteria for the analy $\urcorner$ sis. Mean age was 44 years (range: 34-64). The nipple-areola complex was preserved in 60 cases. In 50 cases, breast reconstruction was performed by direct implant placement. In 57 patients, the incision was placed radially in the upper outer quadrant. Fifty-seven patients did not present complications, and in the rest of the cases the implant was lost in only one (1.4\%) case. An occult breast cancer was detected in only one patient. During follow-up, one patient developed a small carcinoma in the operated breast.

Conclusion: RRM is a valid and safe option for women at high risk for breast cancer, since it signifi $\neg$ cantly reduces the probability of developing the disease, with good aesthetic results and a high level of patient satisfaction.

Keywords: Breast cancer; High risk; Risk reduction mastectomy

\section{Introduction}

Over the past few decades considerable progress has been made in understanding the risk factors for breast cancer, mainly thanks to the development of technology that allowed for the study and sequencing of genome and for the detection of genetic mutations with greater predisposition to hereditary cancer [1,2].
Hereditary breast cancer is less common than sporadic breast cancer; however, women at high risk either because of proven genetic mutations, family history of breast cancer, or personal history represent a gradually increasing fraction due to greater accessibility to genetic testing, more scientific and journalistic information, and the possibility for sciences to respond to this problem nowadays. In fact, Angelina Jolie's decision to undergo risk-reducing mastectomy (RRM) after 


\section{International Journal of Transplantation \& Plastic Surgery}

being diagnosed with a BRCA gene mutation, had a great impact worldwide [3].

Until recently, prophylactic mastectomy was uncommon in our country, as the treating physicians did not recommend the procedure due to insufficient risk categorization, lack of experience with these procedures and fear of poor aesthetic results in healthy women. However, in recent years we have witnessed a shift in the concept of hereditary breast cancer, with more diagnoses of genetic mutations and significant advances in the appropriate management of this population of high-risk patients.

Risk-reducing mastectomy implies total removal of the glandular tissue, with or without removal of the nippleareola complex (NAC) and immediate breast reconstruction, usually based on prosthesis implant. Other terms as preventive or prophylactic mastectomy are rarely used. In high-risk population patients, this surgery has proved to reduce the risk for breast cancer by more than $90 \%[4,5]$ and is currently recommended by the leading organizations and clinical practice guidelines [6-8].

Our University Hospital has a specialized Breast Center. All patients at high risk for breast cancer who request preventive surgery are evaluated by the High-Risk Breast and Ovarian Cancer Clinic, which is made up of a multidisciplinary team of genetician, specialized radiologists, mastologists, and psycho-oncologist. No patient undergoes a risk reduction mastectomy (MRR) if it was not previously evaluated by these professionals.

\section{Material and Methods}

We conducted a retrospective and observational study. The clinical records of the patients undergoing RRM at the Breast Center of the Hospital Universitario Austral (HUA) were reviewed. The analysis included healthy patients undergoing simultaneous bilateral RRM and those with a history of breast cancer who underwent contralateral RRM. Patients with mastectomies performed as treatment of breast cancer were excluded, but those with contralateral mastectomies were included.

High risk for breast cancer was considered in the following situations: documented BRCA1 or BRCA2 gene mutations, or patients with a history of two or more firstdegree relatives with breast cancer or with a more aggressive tumor biology (triple-negative breast cancer, HER2 positive, positive axillary nodes or rapid disease progression). All the patients were evaluated by a geneticist and a psychooncologist before RRM.

Surgical technique: In case of nipple-sparing mastectomy, the incision was placed in the upper outer quadrant or at the inframammary skin incision. In all the cases, a tumescent solution composed by saline, lidocaine, and epinephrine was infiltrated into the subcutaneous plane of the flaps. Then, the superficial dermal flap was dissected leaving the subdermal fat in place. The terminal ducts were dissected as close as possible to the nipple, and a mark was left as reference for the correct histopathological examination. In case of removing the NAC, an oblique skin incision was performed, preserving the rest of the skin covering the breast. The dissection was deepened respecting the pectoralis fascia. Once the breast was resected, the pectoralis major muscle was detached from its inferior and medial costal insertions in the sternum and was raised to create a submuscular pocket. In many occasions, synthetic meshes were used to assist the closure of the muscular plane, suturing it to the subcutaneous cellular tissue one centimeter above the inframammary fold and then to the lower free edge of the pectoralis major. The upper part of a silicone implant or tissue expander is covered by muscle and the lower part by skin or mesh. Aspiration drainage was placed in all cases and removed after 15 days.

Data Collection and analysis: Patient records were reviewed and the following data were obtained: age at surgery; indication of mastectomy; breast reconstruction method, type of skin incision; post-operative complications. Other relevant descriptive data were also obtained.

\section{Results}

Between September 2012 and September 2017, 70 RRM were performed in 49 patients who fulfilled the inclusion criteria for the analysis. Mean age was 44 years (range: 3464). Indications for surgery:

Sixteen healthy patients underwent 32 mastectomies due to documented BRCA1 or BRCA2 gene mutations in seven and a strong family history of breast cancer not documented by genetic testing in nine.

Twenty-eight patients with diagnosis of breast cancer undergoing therapeutic mastectomy underwent contralateral RRM; six of them had documented gene mutation and 22 had strong family history of breast cancer not documented by genetic testing.

Five patients with previous conservative treatment for breast carcinoma, and posterior documented BRCA gene mutation underwent bilateral RRM. In this group, all the patients had prior radiation therapy for breast cancer.

Table 1 shows the type of surgery: nipple-sparing mastectomy in 60 cases $(85,7 \%)$ and skin-sparing mastectomy without NAC preservation in 10 (14.2\%). 


\section{International Journal of Transplantation \& Plastic Surgery}

Axillary sentinel lymph node biopsy was associated in 11 cases. Breast reconstruction was performed with anatomical silicone implant in 50 cases $(71.4 \%)$ and temporary tissue expander followed by replacement with a permanent breast implant in 20 cases $(28.5 \%)$.

\begin{tabular}{|c|c|c|}
\hline Surgical Parameter & $\mathbf{N}$ & $\%$ \\
\hline \multicolumn{3}{|l|}{ Type of surgery } \\
\hline Nipple-Sparing Mastectomy & 60 & 86 \\
\hline $\begin{array}{l}\text { Skin-Sparing Mastectomy (without NAC } \\
\text { preservation) }\end{array}$ & 10 & 14 \\
\hline Simultaneous axillary sentinel node biopsy & 11 & \\
\hline \multicolumn{3}{|l|}{ Breast Reconstruction } \\
\hline Anatomical silicone implant & 50 & 71 \\
\hline $\begin{array}{l}\text { Temporary Tissue Expanser followe by } \\
\text { permanent breast implant }\end{array}$ & 20 & 29 \\
\hline \multicolumn{3}{|l|}{ Type of Skin Incision } \\
\hline Radial incision in upper outer quadrant & 57 & 81 \\
\hline Lozenge-shaped incision including NAC & 9 & 13 \\
\hline Inframammary incision & 2 & 2.8 \\
\hline Peri areolar & 1 & 1.4 \\
\hline Inverted-T incision & 1 & 1.4 \\
\hline
\end{tabular}

Table 1: Surgical Parameters.

The following incisions were used: radial incision in upper outer quadrant in 57 (81.4\%) patients, lozengeshaped incision in nine including the NAC, inframammary fold incision in two, periareolar in one and one inverted-T incision.

Mean hospital length of stay was 1 day (range 1-3). The complications reported are shown in Table 2. There were no complications in 57 mastectomies, six patients developed ischemic complications or wound dehiscence requiring revision surgery without implant loss and four patients presented periprosthetic seroma requiring surgical drainage. Nipple necrosis occurred in one patient and was resected and only two cases presented postoperative infection. Of these two cases, the implant could be preserved in one patient after surgical drainage and revision surgery but had to be removed in the other patient. A total of 13 patients $(18.5 \%)$ required reoperation.

Of the 70 surgical specimens sent to pathological examination, only one $(1.4 \%)$ breast cancer was detected in a patient with a left breast cancer and strong family history of breast cancer who required contralateral RRM. This patient had no clinical evidence or image tests suggestive of contralateral disease, and the pathological examination reported the presence of a 15-mm invasive lobular carcinoma with negative sentinel lymph node.

During follow-up, a high-risk patient with a history of bilateral RRM in 2013 and without known BRCA mutation developed a non-invasive carcinoma of $7 \mathrm{~mm}$ in the right breast that was palpable at 12 o' clock. The patient underwent local resection and radiation therapy, with favorable outcome.

\begin{tabular}{|c|c|c|}
\hline Type of Complication & N & $\mathbf{\%}$ \\
\hline Non-significant complication & 57 & 81 \\
\hline Flap ischemia or wound dehiscence & 6 & 8.5 \\
\hline Periprosthetic seroma & 4 & 5.7 \\
\hline Nipple necrosis & 1 & 1.4 \\
\hline Implant infection & 2 & 2.8 \\
\hline Breast reconstruction failure & 1 & 1.4 \\
\hline
\end{tabular}

Table 2: Postoperative Complications.

\section{Discussion}

Concerns about breast cancer and its consequences generate a high motivation for women at risk to request more screening tests and prevention measures. In our practice, patients commonly request risk-reducing surgery, even if they are not at high risk. Therefore, we strongly believe that the evaluation and therapeutic recommendations should be carried out in the context of multidisciplinary teams trained in the specialty [9].

In our experience, the number of RRM has gradually increased in association with the number of women who accessed genetic screening. Women who have BRCA1 or BRCA2 mutation have a $67 \%$ and $66 \%$ risk, respectively, of being diagnosed with breast cancer during their lifetimes until about age of 80 [10]. Furthermore, in most BRCA mutation patients who develop cancer, the tumors are more aggressive, develop in young women, and generally have a worse prognosis [11]. Faced with this reality, most women with confirmed genetic mutations request RRM, which reduces the probability of developing the disease by $93 \%$. This risk reduction can be even greater when unselected populations are analyzed [12], but since residual glandular tissue may remain after surgery, this risk is never completely eliminated. In our experience, one patient (1.4\%) developed breast cancer after mastectomy, which was detected as a superficial palpable nodule in early stages of the disease. Other experiences also show that, even with very meticulous surgical techniques for breast removal, there is a marginal chance of developing a primary breast cancer [6-8,13-15].

Patients should also be informed that this surgery 


\section{International Journal of Transplantation \& Plastic Surgery}

reduces the risk of developing breast cancer, but to date there is no evidence that RRM confers an overall survival benefit to this group of healthy women [16], and only a few publications based on mathematical models suggest a benefit of up to $7 \%$ in survival in women who would undergo RRM $[17,18]$.

The controversy is greater for contralateral RRM in patients who have already had breast cancer, since the prognosis will usually depend on the first event, and it is not yet clear whether removing the other breast confers any benefit in terms of overall survival [19]. However, the indication for this surgery is intended to decrease the risk for contralateral cancer and is enough motivation for patients to request surgery [9-11,20]. In patients with a known mutation, the probability of developing a contralateral cancer reaches $30 \%$ at 10 years, a percentage that greatly exceeds the risk of contralateral cancer in patients without mutations $(5-6 \%$ at 10 years) [5,12,13,21-23].

Risk-reducing mastectomy presents some challenges in terms of surgical technique, the type of incision used and vascularization of the cutaneous flap, which implies adequate preoperative planning and gentle manipulation of the tissues during surgery [24-26]. There is consistent evidence that removal of the NAC in healthy women does not provide additional benefit and should only be removed in case vitality issues due to ischemia, very large breasts, or upon patient request [27-29].

In our series, a high percentage of patients had no complications while others presented mild complications. However, $18.5 \%$ of the cases has to be reoperated due to adverse events, and reconstruction failed in one patient. Other experiences showed similar results [30,31].

Although we did not analyze the cosmetic results, different publications report that MRR generally causes a negative alteration in body image; however, the degree of general satisfaction is very high, as well as the decrease in anxiety due to the risk of breast cancer [25,32-34]. Thus, according to international publications, most patients would choose surgery again [34-37].

In conclusion, RRM is a valid and safe option for women at high risk for breast cancer, since it significantly reduces the probability of developing the disease, with good aesthetic results and a high level of patient satisfaction. However, this population needs to be assessed by multidisciplinary teams and correctly informed about the risk for breast cancer and the different options for surveillance or risk reduction.

\section{References}

1. Lynch HT, Krush AJ (1971) Genetic predictability in breast cancer risk. Surgical implications. Arch Surg 103(1): 84-88.

2. King MC, Marks JH, Mandell JB, New York Breast Cancer Study Group (2003) Breast and ovarian cancer risks due to inherited mutations in BRCA1 and BRCA2. Science 302(5645): 643-646.

3. Evans DGR, Barwell J, Eccles DM, Collins A, Izatt L, et al. (2014) The Angelina Jolie effect: how high celebrity profile can have a major impact on provision of cancer related services. Breast Cancer Research 16(5): 442

4. Hartmann LC, Schaid DJ, Woods JE, Crotty TP, Myers JL, et al. (1999) Efficacy of bilateral prophylactic mastectomy in women with a family history of breast cancer. $\mathrm{N}$ Engl J Med 340(2): 77-84.

5. Skytte AB, Crüger D, Gerster M, Laenkholm AV, Lang C, et al. (2011) Breast cancer after bilateral risk-reducing mastectomy. Clin Genet 79(5): 431-437.

6. (2014) Alto Riesgo Para Cáncer De Mama Consenso Nacional Inter-Sociedades. Programa Nacional de Consensos Inter-Sociedades Programa Argentino de Consensos de Enfermedades Oncológicas.

7. Paluch-Shimon S, Cardoso F, Sessa C (2016) ESMO Clinical Practice Guidelines for cancer prevention and screening. Annals of Oncology 27(5): 103-110.

8. NCCN Guidelines For Detection, Prevention, \& Risk Reduction. Breast Cancer Risk Reduction.

9. Robson MR, Bradbury AR, Arun B, Domchek SM, Ford JM, et al. (2015) American Society of Clinical Oncology policy statement update: genetic and genomic testing for cancer susceptibility. J Clin Oncol 33(31): 3660-3667.

10. Antoniou A, Pharoah PD, Narod S, Risch HA, Eyfjord JE, et al. (2003) Average risks of breast and ovarian cancer associated with BRCA1 or BRCA2 mutations detected in case Series unselected for family history: a combined analysis of 22 studies. Am J Hum Genet 72(5): 11171130.

11. Mavaddat N, Barrowdale D, Andrulis IL, Domchek SM, Eccles D, et al. (2012) Pathology of breast and ovarian cancers among BRCA1 and BRCA2 mutation carriers: results from the Consortium of Investigators of Modifiers of BRCA1/2 (CIMBA). Cancer Epidemiol Biomarkers Prev 21(1): 134-147.

12. Rebbeck TR, Friebel T, Lynch HT, Neuhausen SL, Veer LV, et al. (2004) Bilateral prophylactic mastectomy reduces breast cancer risk in BRCA1 and BRCA2 mutation carriers: the PROSE Study Group. J Clin Oncol 22(6): 


\section{International Journal of Transplantation \& Plastic Surgery}

$1055-1062$.

13. Meijers Heijboer H, Van Geel B, Van Putten WL, Henzen Logmans SC, Seynaeve C, et al. (2001) Breast cancer after prophylactic bilateral mastectomy in women with a BRCA1 or BRCA2 mutation. N Engl J Med 345(3): 159164.

14. Arver B, Isaksson $\mathrm{K}$, Atterhem $\mathrm{H}$, Baan A, Bergkvist L, et al. (2011) Bilateral prophylactic mastectomy in Swedish women at high risk of breast cancer: a national survey. Ann Surg 253(6): 1147-1154.

15. Evans DG, Baildam AD, Anderson E, Brain A, Shenton A, et al. (2009) Risk reducing mastectomy: outcomes in 10 European centres. J Med Genet 46(4): 254-258.

16. Lostumbo L, Carbine NE, Wallace J (2010) Prophylactic mastectomy for the prevention of breast cancer. Cochrane Database Syst Rev 11: CD002748.

17. Kurian AW, Sigal BM, Plevritis SK (2010) Survival analysis of cancer risk reduction strategies for BRCA $1 / 2$ mutation carriers. J Clin Oncol 28(2): 222-231.

18. Sigal BM, Munoz DF, Kurian AW, Plevritis SK (2012) A simulation model to predict the impact of prophylactic surgery and screening on the life expectancy of BRCA1 and BRCA2 mutation carriers. Cancer Epidemiol Biomark Prev 21(7): 1066-1077.

19. Bedrosian I, Hu CY, Chang GJ (2010) Population-based study of contralateral prophylactic mastectomy and survival outcomes of breast cancer patients. J Natl Cancer Inst 102(6): 401-409.

20. Metcalfe K, Lynch HT, Ghadirian P, Tung N, Olivotto I, et al. (2004) Contralateral breast cancer in BRCA1 and BRCA2 mutation carriers. J Clin Oncol 22(12): 2328-2335.

21. Chung A, Huynh K, Lawrence C, Sim MS, Giuliano A (2012) Comparison of patient characteristics and outcomes of contralateral prophylactic mastectomy and unilateral total mastectomy in breast cancer patients. Ann Surg Oncol 19(8): 2600-2606.

22. Frost MH, Hoskin TL, Hartmann LC, Degnim AC, Johnson JL, et al. (2011) Contralateral prophylactic mastectomy: long-term consistency of satisfaction and adverse effects and the significance of informed decision-making, quality of life, and personality traits. Ann Surg Oncol 18(11): 3110-3116.

23. Collins K, Gee M, Clack A, Wyld L (2017) The psychosocial impact of contralateral risk reducing mastectomy (CRRM) on women: A rapid review. Psychooncology 27(1): 43-52.
24. McDonnell SK, Schaid DJ, Myers JL, Grant CS, Donohue $\mathrm{JH}$, et al. (2001) Efficacy of contralateral prophylactic mastectomy in women with a personal and family history of breast cancer. J Clin Oncol 19(19): 3938-3943.

25. Herrinton LJ, Barlow WE, Yu O, Geiger AM, Elmore JG, et al. (2005) Efficacy of prophylactic mastectomy in women with unilateral breast cancer: a cancer research network project. J Clin Oncol 23(19): 4275-4286.

26. Van Sprundel TC, Schmidt MK, Rookus MA, Brohet R, Van Asperen CJ, et al. (2005) Risk reduction of contralateral breast cancer and survival after contralateral prophylactic mastectomy in BRCA1 or BRCA2 mutation carriers. Br J Cancer 93(3): 287-292.

27. Tokin C, Weiss A, Wang-Rodriguez J, Blair SL (2012) Oncologic safety of skin-sparing and nipple-sparing mastectomy: a discussion and review of the literature. Int J Surg Oncol pp: 1-8.

28. La Cruz LD, Moody AM, Tappy EE, Blankenship SA, Hecht EM (2015) Overall survival, disease-free survival, local recurrence, and nipple-areolar recurrence in the setting of nipple-sparing mastectomy: a meta-analysis and systematic review. Ann Surg Oncol 22(10): 3241-3249.

29. Murthy V, Chamberlain RS (2013) Defining a place for nipple sparing mastectomy in modern breast care: an evidence based review. Breast J 19(6): 571-581.

30. Zion SM, Slezak JM, Sellers TA, Woods JE, Arnold PG, et al. (2003) Reoperations after prophylactic mastectomy with or without implant reconstruction. Cancer 98(10): 2152-2160.

31. Barton MB, West CN, Liu AIL, Harris EL, Rolnick SJ, et al. (2005) Complications following bilateral prophylactic mastectomy. J Natl Cancer Inst Monogr 35: 61-66.

32. Gopie JP, Mureau MA, Seynaeve C, Ter Kuile MM, Menke Pluymers MBE, et al. (2013) Body image issues after bilateral prophylactic mastectomy with breast reconstruction in healthy women at risk for hereditary breast cancer. Fam Cancer 12(3): 479-487.

33. Brandberg Y, Sandelin K, Erickson S, Jurell G, Liljegren A, et al. (2008) Psychological reactions, quality of life, and body image after bilateral prophylactic mastectomy in women at high risk for breast cancer: a prospective 1-year follow-up study. J Clin Oncol 26(24): 3943-3949.

34. Braude L, Kirsten L, Gilchrist J, Juraskova I (2017) A systematic review of women's satisfaction and regret following risk-reducing mastectomy. Patient Educ Couns 100(12): 2182-2189. 


\section{International Journal of Transplantation \& Plastic Surgery}

35. Payne DK, Biggs C, Tran KN, Massie MJ (2000) Women's regrets after bilateral prophylactic mastectomy. Ann Surg Oncol 7(2): 150-154.

36. Gahm J, Wickman M, Brandberg Y (2010) Bilateral prophylactic mastectomy in women with inherited risk of breast cancer: prevalence of pain and discomfort, impact on sexuality, quality of life and feelings of regret two years after surgery. Breast 19(6): 462-469.

37. Tondu T, Thiessen F, Wiebren A (2016) Prophylactic Bilateral Nipple-sparing Mastectomy and a Staged Breast Reconstruction Technique: Preliminary Results. Breast Cancer (Auckl) 10: 185-189. 